УДК 616.314-077:616.31-002

DOI: 10.26435/UC.V0I3(32).347

\author{
А.А. Ворожко \\ ГОО ВПО «Донецкий национальный медицинский университет имени М. Горького», Донецк
}

\title{
КЛИНИЧЕСКИЕ СИМПТОМЫ И КЛИНИКО-АНАМНЕСТИЧЕСКИЕ ПРЕДИКТОРЫ СТОМАТИТА НА СЬЕМНЫЕ ЗУБНЫЕ ПРОТЕЗЫ ИЗ АКРИЛОВЫХ ПОЛИМЕРОВ
}

Адентия, частичная или полная, является одним из наиболее распространённых стоматологических заболеваний, которым по данным ВОЗ страдает до 75\% населения. В России целостность зубных рядов нарушена у 70\% населения в возрасте 20-50 лет и этот показатель неуклонно растет. Поэтому потребность в ортопедической стоматологической помощи не только не сокращается, но, к сожалению, и увеличивается. Кроме того, количество лиц, нуждающихся в съемном протезировании, из года в год имеет тенденцию к омоложению [1].

Из всего перечня ортопедической помощи доля съемного протезирования составляет до 80 \% [2, 3]. По данным отдельных авторов, в 7280\% случаях для изготовления съёмных зубных протезов используют акриловые полимеры [3, 4], главными преимуществами которых являются доступность, дешевизна, технологичность и простота изготовления.

Вместе с тем необходимо отметить, что на акриловые базисные полимеры, также, как и на безакриловые материалы, могут развиваться протезные стоматиты, среди которых наибольшей актуальностью характеризуются воспалительные реакции аллергического генеза [5]. Причем, следует учитывать, что определение предрасположенности к аллергии, диагностика и лечение аллергического стоматита являются крайне сложными задачами даже для врачей с большим клиническим опытом и имеющимися в арсенале возможностями назначать аллергологические исследования пациенту в условиях современной лаборатории [6, 7].

Поэтому решение таких задач как определение предрасположенности к развитию протезного стоматита, диагностика аллергического ответа организма на протезные материалы представляется актуальным и в теоретическом, и в практическом отношениях [8].

\section{ЦЕЛЬИССЛЕДОВАНИЯ}

Изучить частоту возникновения и клинические проявления стоматитов у пациентов после протезирования акриловыми полимерами и установить клинико-анамнестические предикторы их развития.

\section{МАТЕРИАЛ И МЕТОДЫ}

Обследовано 54 пациента в возрасте от 42 до 88 лет. Медиана возраста (Ме) и интерквартильный размах (Q1-Q3) составили соответственно 62,0 года и 56,0-70,0 лет. Среди обследованных лиц было 38 женщин и 16 мужчин.

Все пациенты нуждались в установке частичных съемных протезов. Они имели дефекты зубных рядов I (двусторонний концевой дефект), II (односторонний концевой дефект), III (включенные дефекты в области жевательных зубов) и IV (дефекты в области фронтального участка зубного ряда) классов по Кеннеди [9]. Противопоказания к протезированию отсутствовали. Протезы готовились из акрилового полимера «Белакрил-М ГО» («Владмива», Россия). Процесс изготовления их состоял из ряда последовательных клинических и лабораторных этапов [10].

Пациенты дважды проходили клиникоанамнестическое обследование (до и спустя 1 месяц после установки протеза). При клиническом исследовании использовали анкету, разработанную исходя из установленных и предполагаемых факторов риска развития протезных стоматитов, аллергических реакций. При помощи структурированного вопросника выясняли анамнестические данные пациентов: наличие профессиональных вредностей (контакты с химическими аллергенами, лекарствами, красителями, полимерами и т.д.), вредных привычек (курение, прием алкоголя). Особое внимание

(C) А.А. Ворожко, 2019

(c) Университетская Клиника, 2019 
уделялось наличию и характеристике аллергической патологии (атопический дерматит, поллиноз, аллергическая крапивница, ангионевротический отек, анафилактический шок, бронхиальная астма и т.д.) у пациентов и их ближайших родственников. Помимо вышеуказанного исследовался стоматологический анамнез (зубные отложения, гиперемия и отечность слизистой, кровоточивость десен, высыпания на слизистой рта и т.д.) и наличие сопутствующей патологии (сердечно-сосудистая и эндокринная патология, заболевания органов желудочнокишечного тракта, почек и т.д.).

Математическую обработку полученных результатов выполняли с помощью прикладной статистической программы «MedStat». Значимость различий в частоте клиникоанамнестических данных между двумя выделенными группами (пациенты со стоматитом и без стоматита) оценивали при помощи $\chi 2$ (анализ таблиц сопряженности - таблицы $\mathrm{k} \times \mathrm{m})$. Статистически значимыми отличия считались при $\mathrm{p}<0,05$.

\section{РЕЗУЛЬТАТЫ И ОБСУЖДЕНИЕ}

Проведенными исследованиями установлено, что из 54 больных, которым были установлены съемные протезы из акриловых полимеров, у 16 пациентов (29,6\%) спустя 1 месяц наблюдения были выявлены симптомы стоматита. Основными клиническими проявлениями протезного стоматита (табл. 1.) были жалобы на дискомфорт в полости рта, болезненные ощущения, чувство жжения и покалывания слизистой полости рта (в 100 \% случаев), сухости рта (в 50,0\% случаев), нарушения чувствительности и изменения вкусовых ощущений (в 68,8\% случаев), наличие гиперемии и отека слизистых рта (в 100,0\% случаев). У 4-х из 16 лиц отмечались головные боли, нарушение сна. 2 пациента при осмотре имели единичные точечные кровоизлияния слизистых. У 1-го пациента были установлены признаки обострения атопического дерматита.

Сроки появления клинических симптомов протезного стоматита отражены на рисунке (см. рис.). Следует отметить, что подавляющее большинство пациентов (12 из 16) отмечало первые признаки стоматита, начиная с 7-15 дня после установки протеза.

Результаты анализа клинико-анамнестических данных у обследованных пациентов представлены в таблице 2. Оценка стоматологического анамнеза показала, что наличие в анамнезе или на момент осмотра перед протезированием у пациентов зубных отложений, гиперемии, отечности, высыпаний на слизистой рта, кровоточивости десен существенно не влияло на риск развития протезного стоматита $(\mathrm{p}>0,05)$. Не отличались (p>0,05) больные протезным стоматитом от группы лиц, не имеющих осложнений после протезирования, также и наличием вредных привычек (алкоголь, курение), контактов на работе с химическими вредностями (полимеры, краски и т.д.), лекарственными препаратами.

Кроме того, две выделенные группы пациентов (с и без протезных стоматитов) не отличались $(\mathrm{p}>0,05)$ частотой выявления сопутствующей патологии - остеохондроза, хронической патологии желчного пузыря, поджелудочной железы, желудка, сердечно-сосудистых и рев-

Характеристика клинических проявлений стоматита у пациентов $(\mathrm{n}=16)$

Таблица 1. через 1 месяц после протезирования акриловыми конструкциями

\begin{tabular}{lc}
\multicolumn{1}{c}{ Клинические симптомы } & $\begin{array}{c}\text { Частота встречаемости симптомов } \\
\text { у пациентов с протезным стоматитом }\end{array}$ \\
\hline \hline Дискомфорт в полости рта & 16 \\
\hline Чувство жжения и покалывания слизистой полости рта & 16 \\
\hline Гиперемия и отек слизистых рта & 16 \\
\hline $\begin{array}{l}\text { Нарушение чувствительности слизистой полости рта, } \\
\text { изменения вкуса }\end{array}$ & 11 \\
\hline Сухость слизистой полости рта & 8 \\
\hline Раздражительность & 6 \\
\hline Головные боли, нарушения сна & 4 \\
\hline Точечные кровоизлияния слизистой полости рта & 2 \\
\hline Обострение атопического дерматита & 1 \\
\hline
\end{tabular}


Таблица 2

Клинико-анамнестическая характеристика полости рта, вредные привычки и профессиональные вредности у пациентов, у которых впоследствии развился протезный стоматит

\begin{tabular}{|c|c|c|c|}
\hline \multirow{2}{*}{ Показатель } & \multicolumn{2}{|c|}{$\begin{array}{c}\text { Частота регистрации клинико- } \\
\text { анамнестического показателя у пациентов: }\end{array}$} & \multirow{2}{*}{$\mathrm{P}$} \\
\hline & $\begin{array}{c}\text { с протезным } \\
\text { стоматитом }(\mathrm{n}=16) \\
\end{array}$ & $\begin{array}{l}\text { без протезного } \\
\text { стоматита }(\mathrm{n}=38) \\
\end{array}$ & \\
\hline Наличие зубных отложений & 3 & 9 & 0,970 \\
\hline $\begin{array}{l}\text { Гиперемия, отечность и высыпания } \\
\text { на слизистой рта }\end{array}$ & 2 & 4 & 0,793 \\
\hline Наличие кровоточивости десен & 3 & 9 & 0,970 \\
\hline Курение (в количестве более 5 сигарет в день) & 5 & 9 & 0,811 \\
\hline $\begin{array}{l}\text { Прием алкоголя (в количестве более } 20 \text { грамм } \\
\text { спирта в неделю) }\end{array}$ & 4 & 9 & 0,807 \\
\hline $\begin{array}{l}\text { Наличие профессиональных химических } \\
\text { вредностей (контакты с полимерами, } \\
\text { красками, асбестом, тяжелыми металлами и т.д. }\end{array}$ & 2 & 1 & 0,427 \\
\hline $\begin{array}{l}\text { Наличие контактов с лекарственными } \\
\text { препаратами (фармацевты, провизоры) }\end{array}$ & 1 & 1 & 0,885 \\
\hline
\end{tabular}

Сопутствующая патология у пациентов, у которых развился стоматит

Таблица 3. спустя 1 месяц после установления протезов из акрила

\begin{tabular}{|c|c|c|c|}
\hline \multirow{2}{*}{ Сопутствующая патология } & \multicolumn{2}{|c|}{$\begin{array}{c}\text { Частота регистрации сопутствующей } \\
\text { патологии у пациентов: }\end{array}$} & \multirow{2}{*}{$\mathrm{P}$} \\
\hline & $\begin{array}{l}\text { с протезным сто- } \\
\text { матитом }(\mathrm{n}=16) \\
\end{array}$ & $\begin{array}{l}\text { без протезного } \\
\text { стоматита }(\mathrm{n}=38) \\
\end{array}$ & \\
\hline Хронический холецистит & 3 & 4 & 0,706 \\
\hline Хронический панкреатит & 1 & 3 & 0,721 \\
\hline Хронический гастрит & 0 & 4 & 0,436 \\
\hline Ишемическая болезнь сердца & 2 & 1 & 0,427 \\
\hline Гипертоническая болезнь & 3 & 4 & 0,706 \\
\hline Вегетососудистая дистония & 1 & 2 & 0,614 \\
\hline Хронический тиреоидит, гипотиреоз & 2 & 1 & 0,427 \\
\hline Ревматологические заболеваний & 1 & 2 & 0,614 \\
\hline Остеохондроз & 3 & 7 & 0,723 \\
\hline Аллергические заболевания у пациента & 8 & 7 & 0,042 \\
\hline $\begin{array}{l}\text { Аллергические заболевания у близких } \\
\text { родственников (мать, отец) }\end{array}$ & 4 & 5 & 0,506 \\
\hline
\end{tabular}

матологических заболеваний, патологии щитовидной железы (табл. 3.). Вместе с тем, необходимо отметить, что среди больных, ответивших на протезирование развитием стоматита, положительный аллергологический анамнез имели 8 пациентов (8 из 16), тогда как среди остальных - всего лишь 7 (7 из 38). Различие частот вышеуказанного показателя в двух группах достигало достоверного уровня ( $\mathrm{p}=0,042)$.

Таким образом, результаты выполненных исследований демонстрируют достаточно высокую частоту стоматитов (29,6\%) спустя 1 месяц после установки частичных съемных протезов из акриловых полимеров. Полученные данные согласуются с результатами аналогичных исследований, свидетельствующих о том, что аллергическая непереносимость протезных материалов с каждым годом растет и распространенность протезных стоматитов достигает 40,0\% [5, 11-13]. 


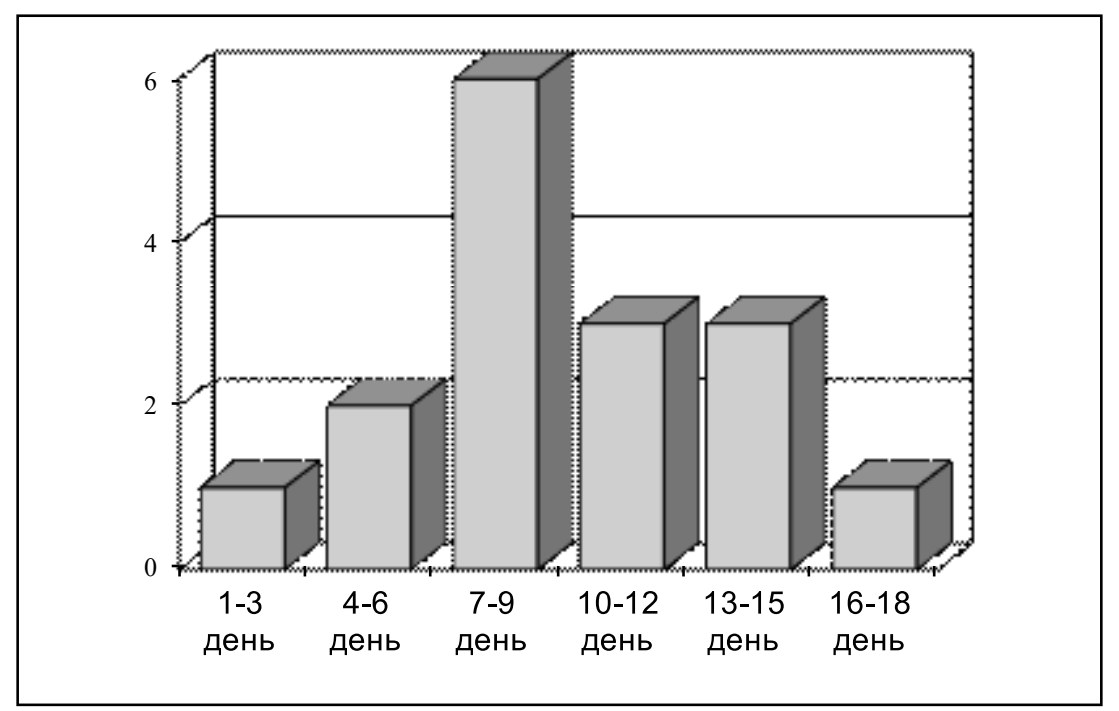

Рисунок. Распределение пациентов (n=16) с протезным стоматитом в зависимости от срока появления симптомов после установки протеза

Примечание: по оси ординат - количество пациентов со стоматитом, по оси абсцисс - день появления стоматита после установки протеза

Важно отметить то, что по этиологии выделяют несколько форм протезных стоматитов (травматические, токсические, аллергические и др.) и, к сожалению, не всегда удается эффективно провести между ними дифференциальную диагностику. Поэтому природу выявленных стоматитов у 16 пациентов вряд ли можно определить однозначно. Тем не менее, ряд признаков свидетельствует об аллергическом характере воспалительного процесса. Так, в большинстве случаев симптомы воспаления слизистой ротовой полости у пациентов (у 12 из 16) появились на 7-15 день после протезирования. А это тот срок, который как раз и необходим для формирования у пациентов сенсибилизации к компонентам протеза. В пользу аллергической этиологии стоматита свидетельствуют и выявленные характерные клинические симптомы, а также установленная связь между развитием стоматита и наличием у пациента аллергического заболевания. Причем, сведения об аллергологическом анамнезе, выяснение которого доступно на обычном клиническом осмотре пациента и не сопряжено с особыми затратами времени и средств, могут иметь определенное значение в деятельности практического врача при определении риска развития протезного стоматита у каждого конкретного больного. Немаловажны полученные результаты и для определения мероприятий, направленных на предупреждение вышеуказанного осложнения после протезирования.

\section{В Ы В О Д Ы}

1. В 29,6\% случаев установка съемных протезов из акриловых полимеров через 1 месяц после протезирования сопровождается симптомами стоматита.

2. В 75,0\% случаев первые признаки стоматита (дискомфорт в полости рта, чувство жжения, покалывания, сухости слизистой полости рта, гиперемия и отек слизистых, нарушение чувствительности, изменение вкусовых ощущений и т.д.) развиваются с 7-15 дня после установки протеза.

3. Полученныерезультатынеобходимоучитывать при прогнозировании развития протезных стоматитов и использовать для разработки индивидуальных схем лечебно-профилактических мероприятий с целью предупреждения осложнений после протезирования. 


\section{А.А. Ворожко}

ГОО ВПО «Донецкий национальный медицинский университет имени М. Горького», Донецк

\section{КЛИНИЧЕСКИЕ СИМПТОМЫ И КЛИНИКО-АНАМНЕСТИЧЕСКИЕ ПРЕДИКТОРЫ СТОМАТИТА НА СЪЕМНЫЕ ЗУБНЫЕ ПРОТЕЗЫ ИЗ АКРИЛОВЫХ ПОЛИМЕРОВ}

Цель исследования. Изучить частоту возникновения и клинические проявления стоматитов у пациентов после протезирования акриловыми полимерами и установить клинико-анамнестические предикторы их развития.

Материал и методы. Обследовано 54 пациента в возрасте от 42 до 88 лет. Среди обследованных лиц было 38 женщин и 16 мужчин. Все пациенты нуждались в установке частичных съемных протезов. Противопоказания к протезированию отсутствовали. Протезы готовились из акрилового полимера Белакрил-М («Владмива», Россия). Процесс изготовления протезов соответствовал стандартной методике. Пациенты дважды проходили клинико-анамнестическое обследование (до и спустя 1 месяц после установки протеза). При клиническом исследовании использовали анкету, разработанную исходя из установленных и предполагаемых факторов риска развития протезных стоматитов, аллергических реакций. Учитывалось наличие профессиональных вредностей, вредных привычек, аллергических заболеваний, стоматологических нарушений, сопутствующей патологии. Математическую обработку полученных результатов выполняли с помощью прикладной статистической программы «MedStat». Для сравнения частоты выявления тех или иных клинико-анамнестических признаков в группах использовался критерий $\chi 2$. Статистически значимыми отличия считались при р<0,05.
Результаты. Установлено, что спустя 1 месяц после протезирования развились симптомы стоматита в 29,6\% случаев. Клинические проявления стоматита включали дискомфорт в полости рта, чувство жжения и покалывания слизистой полости рта (100\% случаев), сухость рта (62,5\% случаев), нарушение чувствительности и изменения вкусовых ощущений $(56,3 \%)$, наличие гиперемии и отека слизистых рта $(100,0 \%$ случаев), головные боли и нарушение сна $(25,0 \%)$, единичные точечные кровоизлияния слизистых $(12,5 \%)$, обострение атопического дерматита $(6,3 \%)$. У большинства пациентов $(75,0 \%)$ первые признаки стоматита возникали на 7-15 день после протезирования. Две выделенные группы пациентов (с и без протезных стоматитов) существенно не отличались (p>0,05) клинико-анамнестическими характеристиками на момент первичного обращения за стоматологической помощью. Однако установлено, что развитие протезного стоматита имело положительную связь ( $\mathrm{p}=0,042)$ с наличием у пациентов аллергического заболевания.

Заключение. Сведения об аллергологическом анамнезе пациента целесообразно использовать при определении риска развития протезного стоматита у каждого конкретного больного и для определения индивидуальных схем лечебно-профилактических мероприятий.

Ключевые слова: адентия, протезирование, акрил, стоматиты.

\section{A.A. Vorozhko}

\section{SEI HPE «M. Gorky Donetsk National Medical University», Donetsk}

\section{CLINICAL SYMPTOMS AND CLINICAL AND ANAMNESTIC PREDICTORS OF STOMATITIS ON REMOVABLE DENTURES OF ACRYLIC POLYMER}

Purpose of the study. To study the incidence and clinical implications of stomatitis in patients after denture treatment with acrylic polymers and to establish clinical and anamnestic predictors of stomatitis progression.

Material and methods. A total of 54 patients aged 42 to 88 years were examined ( 38 females and 16 males). All patients required the removable partial denture treatment. There were no contraindications to denture treatment. Dentures were made of acrylic polymer Belacryl-M («Vladmiva», Russia). The process of dentures manufacturing conforms to the standard technology. Patients underwent clinical and anamnestic examination twice (before the denture treatment and 1 month after). In a clinical study, a questionnaire was developed based on the established and assumed risk factors for the development of denture stomatitis and allergic reactions. The presence of occupational hazards, bad habits, allergic diseases, dental disorders, comorbidities was considered. Mathematical processing of the obtained results was performed using the MedStat applied statistical application. The $\chi 2$ criteria were taken. Statistically significant differences were considered at $\mathrm{p}<0.05$.

Results. It was established that 1 month after denture treatment, symptoms of stomatitis developed in $29.6 \%$ of cases. Clinical implications of stomatitis included oral discomfort, oral mucosa burning and tingling (100\% of cases), dry mouth (62.5\% of cases), impaired sensitivity and taste change (56.3\% of cases), the presence of the oral mucosa hyperemia and swelling (100.0\% of cases), headaches and sleep disturbance (25.0\% of cases), few mucosal pinpoint hemorrhages ( $12.5 \%$ of cases), exacerbation of atopic dermatitis (6.3\% of cases). In the majority of patients $(75,0 \%)$, the first signs of stomatitis appeared on 7-15 days after denture treatment. The two selected groups of patients (with and without denture stomatitis) were not significantly different ( $p>0.05)$ from clinical and anamnestic characteristics at the time of the initial dental visit. However, it was established that the development of denture stomatitis had relation $(p=0,042)$ with the allergic disease in patients.

Conclusion. It is advisable to use the patient's allergological anamnesis data for determining the risk of denture stomatitis progression in every patient and for individual therapy and preventive measures specification.

Key words: adentia, denture treatment, acryl, stomatitis. 


\section{ЛИТЕРАТУРА}

1. Шхагапсоева К.А., Шогенова Ж.Л., Карданова С.Ю. Состояние слизистой оболочки полости рта у лиц, пользующихся съемными протезами. Успехи современной науки. 2017; 12: 27-30.

2. Бровко В.В., Колесникова Ю.В., Онуфриев А.Б., Малый А.Ю. Результаты ортопедического лечения частичного отсутствия зубов у пожилых пациентов. Российская стоматология. 2009; $1: 55-59$.

3. Булгакова А.И., Шафеев И.Р., Галеев Р.М. Клиническая характеристика пациентов с дефектами твердых тканей зубов и зубных рядов с различными ортопедическими конструкциями. Медицинский вестник Башкортостана. 2014; 6: 44-47.

4. Жолудев С.Е., Гетте С.А. Решение проблемы адаптации к съемным конструкциям зубных протезов при полной утрате зубов. Проблемы стоматологии. 2016; 3: 46-51.

5. Карпук И.Ю. Спектр антител к кандидам и акрилу у пациентов с протезным стоматитом. Современная стоматология. 2017; 2: 73-76.

6. Неотложная помощь в стоматологии: пособие по производственной практике по стоматологии. Ред. Клёмин В.А. Донецк: Издатель Заславский Ю.А.; 2014. 352.

7. Клёмин В.А., Ворожко А.А. Современное состояние вопроса выбора материала для ортопедического лечения больных, нуждающихся в съемном протезировании. Дальневосточный медицинский журнал. 2015; 1 : 41-46.

8. Майборода Ю.Н., Гоман М.В., Урясьева Э.В. Непереносимость материалов протезных конструкций. Медицинский вестник Северного Кавказа. 2014; 9 (3): 286291. doi:10.14300/mnnc.2014.09082

9. Аболмасов Н.Г., Аболмасов Н.Н., Бычков В.А., АльХаким А. Ортопедическая стоматология: учебник. Москва: МЕДпресс-информ; 2002: 258.

10. Лебеденко И.Ю., Каливарджиян Э.С. Ортопедическая стоматология. Москва; 2014: 186.

11. Лебедев К.А., Митронин А.В., Понякина И.Д. Непереносимость зубопротезных материалов. Москва; 2018. 208.

12. Шутурминский В. Г. Результаты изучения распространенности протезных стоматитов у лиц, протезируемых съемными пластиночными протезами. Интегративная антропология. 2015; $1: 50-54$.

13. Ivkovic N., Božović D., Ristic S., Mirjanić V., Janković O. The residual monomer in dental acrylic resin and its adverse effects. Contemporary Materials. 2013; 4: 84-91.

\section{REFERENCES}

1. Shkhagapsoeva K.A., Shogenova Zh.L., Kardanova S.Yu. Sostoyanie slizistoi obolochki polosti rta u lits, pol'zuyushchikhsya s"emnymi protezami. Uspekhi sovremennoi nauki. 2017; 12: 27-30 (in Russian).

2. Brovko V.V., Kolesnikova Yu.V., Onufriev A.B., Malyi A.Yu. Rezul'taty ortopedicheskogo lecheniya chastichnogo otsutstviya zubov u pozhilykh patsientov. Rossiiskaya stomatologiya. 2009; 1: 55-59 (in Russian).

3. Bulgakova A.I., Shafeev I.R., Galeev R.M. Klinicheskaya kharakteristika patsientov s defektami tverdykh tkanei zubov i zubnykh ryadov s razlichnymi ortopedicheskimi konstruktsiyami. Meditsinskii vestnik Bashkortostana. 2014; 6: 44-47 (in Russian).

4. Zholudev S.E., Gette S.A. Reshenie problemy adaptatsii k s"emnym konstruktsiyam zubnykh protezov pri polnoi utrate zubov. Problemy stomatologii. 2016; 3: 46-51 (in Russian).

5. Karpuk I.Yu. Spektr antitel k kandidam i akrilu u patsientov s proteznym stomatitom. Sovremennaya stomatologiya. 2017; 2: 73-76 (in Russian).

6. Neotlozhnaya pomoshch' $\mathrm{v}$ stomatologii: posobie po proizvodstvennoi praktike po stomatologii. Red. Klemin V.A. Donetsk: Izdatel' Zaslavskii Yu.A.; 2014. 352 (in Russian).

7. Klemin V.A., Vorozhko A.A. Sovremennoe sostoyanie voprosa vybora materiala dlya ortopedicheskogo lecheniya bol'nykh, nuzhdayushchikhsya v s"emnom protezirovanii. Dal'nevostochnyi meditsinskii zhurnal. 2015; 1: 41-46 (in Russian).

8. Maiboroda Yu.N., Goman M.V., Uryas'eva E.V. Neperenosimost' materialov proteznykh konstruktsii. Meditsinskii vestnik Severnogo Kavkaza. 2014; 9 (3): 286-291 (in Russian). doi:10.14300/mnnc.2014.09082

9. Abolmasov N.G., Abolmasov N.N., Bychkov V.A., Al'-Khakim A. Ortopedicheskaya stomatologiya: uchebnik. Moskva: MEDpress-inform; 2002: 258 (in Russian).

10. Lebedenko I.Yu., Kalivardzhiyan E.S. Ortopedicheskaya stomatologiya. Moskva; 2014: 186 (in Russian).

11. Lebedev K.A., Mitronin A.V., Ponyakina I.D. Neperenosimost' zuboproteznykh materialov. Moskva; 2018. 208 (in Russian).

12. Shuturminskii V. G. Rezul'taty izucheniya rasprostranennosti proteznykh stomatitov u lits, proteziruemykh s"emnymi plastinochnymi protezami. Integrativnaya antropologiya. 2015; 1: 50-54 (in Russian).

13. Ivkovic N., Božović D., Ristic S., Mirjanić V., Janković O. The residual monomer in dental acrylic resin and its adverse effects. Contemporary Materials. 2013; 4: 84-91. 